\title{
Neonatal Coronary Revascularization: Six-Year Follow-up Period
}

\author{
Michael F. Swartz • Matthew P. Schiralli • \\ George M. Alfieris
}

Received: 19 April 2010/Accepted: 5 August 2010/Published online: 25 August 2010

(C) Springer Science+Business Media, LLC 2010

The arterial switch operation used to treat transposition of the great arteries associated with an intramural coronary artery can lead to either early or late myocardial ischemia [1]. Previous reports have demonstrated that arterial revascularization during the neonatal period using the internal mammary artery is possible $[1,2]$. However, the mid- and long-term patency is unknown.

We present images from coronary catheterization of a left internal mammary artery (LIMA) revascularization of the left anterior descending coronary artery after an arterial switch in which a single coronary ostia gave rise to an intramural left coronary artery. Comparison of Fig. 1a, b, in which selective angiography was performed at 1 and 6 years, demonstrated that the LIMA graft supplied the blood for the entire left coronary circulation, and that after 6 years, the LIMA continued to grow in size, supplying blood to the myocardium.

The presence of an intramural coronary artery is known to increase the incidence of peri- and postoperative ischemia during the arterial switch operation [1,2]. Previous data have demonstrated an increased risk for stenosis when the saphenous vein is used as a conduit to treat myocardial ischemia within the neonatal period [2]. For this reason surgeons have reported their experience in using either the left or right internal mammary artery for revascularization during the neonatal period [1, 2]. However, no mid- or long-term followup evaluations have been reported regarding the patency of the internal mammary used during the neonatal period.

Despite favorable short-term results from the use of mammary artery grafts to reperfuse the myocardium, it was

M. F. Swartz $(\bowtie) \cdot$ M. P. Schiralli · G. M. Alfieris

Department of Surgery, University Rochester, Strong Memorial

Hospital, 601 Elmwood Avenue, Rochester, NY 14582, USA

e-mail: michael_swartz@urmc.rochester.edu
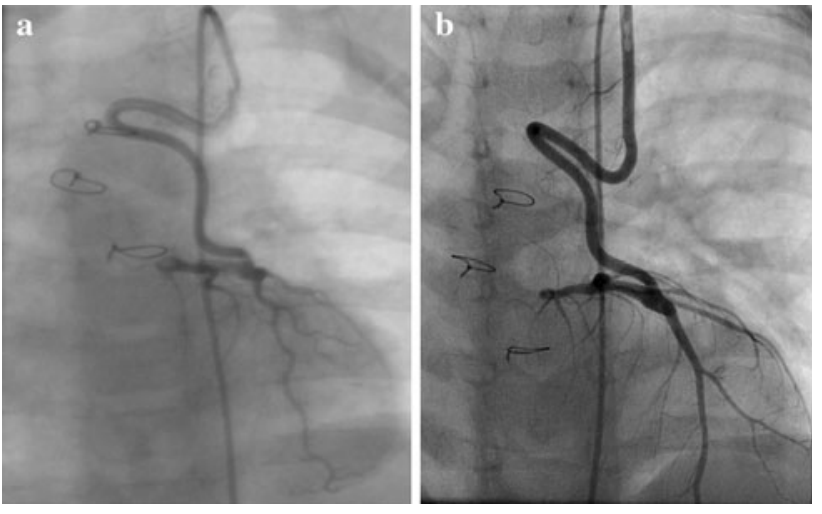

Fig. 1 Catheterization of the left internal mammary at 1 year (a) and 6 years (b) demonstrating a widely patent mammary artery supplying the left coronary circulation

unknown whether the internal mammary artery could supply sufficient coronary blood flow to support the ongoing growth of the heart [3]. Comparison of Fig. 1a, b demonstrates for the first time the ability of a LIMA graft to supply the left coronary circulation with blood flow adequate to keep up with myocardial growth.

\section{References}

1. Brackenbury E, Gardiner H, Chan K, Hickey M (1998) Internal mammary artery to coronary artery bypass in paediatric cardiac surgery. Eur J Cardiothorac Surg 14:639-642

2. Day RW, Laks H, Drinkwater DC (1992) The influence of coronary anatomy on the arterial switch operation in neonates. J Thorac Cardiovasc Surg 104:706-712

3. Yaku H, Nunn GR, Sholler GF (1997) Internal mammary artery grafting in a neonate for coronary hypoperfusion after arterial switch. Ann Thorac Surg 64:543-544 